Jana Pastorkova - Martina Jackova - Filip Pastorek - Zuzana Florkova - Juliana Drabikova

\title{
EFFECT OF PHOSPHATING TEMPERATURE ON SURFACE PROPERTIES OF MANGANESE PHOSPHATE COATING ON HSLA STEEL
}

A phosphating process modified for a high-strength low-alloy (HSLA) steel was performed at various temperatures and influence on the surface properties of the Domex steel covered by manganese phosphate (MnP) was investigated by electrochemical corrosion tests supported by a photo documentation performed by the SEM. Corrosion measurements were performed in $0.1 \mathrm{M} \mathrm{NaCl}$ solution at $22 \pm 2{ }^{\circ} \mathrm{C}$ using electrochemical impedance spectroscopy and potentio-dynamic polarisation in order to obtain thermodynamic and kinetic corrosion characteristics and individual elements of equivalent circuits. It is that a temperature of the phosphating process has a very significant effect on protection properties of the created manganese phosphate coating on the Domex steel and needs to be strictly monitored. According to results of corrosion testing and surface morphology observations, the optimal temperature for the phosphating process on the tested Domex steel was chosen.

Keywords: HSLA steel, corrosion properties, manganese phosphate, surface treatment

\section{Introduction}

At present, the trend is to replace conventional structural steels with high-strength low-alloy steels. The HSLA steels have been developed to replace carbon steels in order to reduce the weight of structures. Their biggest advantage is a weight to strength ratio. Using the HSLA steels instead of conventional carbon steels can save up to $20 \%$ of weight while maintaining the high strength, stiffness and toughness of a structure [1-3]. However the HSLA steels are also attacked by common types of corrosion like standard steels [1], hence their surface needs to be protected by the application of surface treatments. Phosphating is one of the simple, affordable and inexpensive processes for formation of the surface conversion layers. Individual types of phosphating are a preferred surface treatment for the majority of metallic materials. The phosphate coatings improve corrosion resistance and abrasion resistance, increase adhesion at a metal-paint interface, serve as carriers for lubricants, and at the same time exhibit relatively low costs compared to other paint systems and coatings. The main types of phosphating include manganese, ferrous and zinc phosphating. The manganese phosphate has high mechanical resistance and good sliding properties. Good adhesion, distribution and uniform crystal size of this phosphate type result in increased corrosion resistance [4-8]. As listed by Narayanan [9], phosphating may be performed at temperatures ranging from $30-99{ }^{\circ} \mathrm{C}$ and processing time can be varied from a few seconds to several minutes depending on the nature of the metal to be coated, thickness and weight of a coating required and a bath composition. The effect of phosphating bath temperature on various surface characteristics of standard carbon and CrMoV steels was studied by some authors [10-11]. However, the research on corrosion resistance evolution of the MnP coating, prepared by the manganese phosphating on the HSLA steel at various temperatures, was not revealed yet. Hence, the aim of this paper is to optimize the phosphating temperature in order to reach the MnP coating on the Domex steel with the most protective character.

\section{Experimental material and methods}

The high-strength low-alloy Domex 700 steel without additional heat treatment was used as the experimental material. The chemical composition of the Domex 700 is shown in Table 1.

The samples of the experimental material for phosphating and electrochemical tests were prepared with dimensions of $80 \pm 0.1 \times 20 \pm 0.1 \times 5 \pm 0.1 \mathrm{~mm}$ (Figure 1). A $3 \mathrm{~mm}$ diameter hole was subsequently drilled into samples to allow suspension of samples during the phosphating.

Two different electrochemical measurement techniques were used to compare and determine the corrosion resistance of the Domex 700 steel after phosphating at different temperatures: the potentio-dynamic polarization measurements (PD) and the electrochemical impedance spectroscopy (EIS) measurements. A solution of $0.1 \mathrm{M} \mathrm{NaCl}$ (simulating an environment containing aggressive chloride ions) was chosen

Jana Pastorkova, Martina Jackova, Filip Pastorek*, Zuzana Florkova, Juliana Drabikova

University of Zilina, Slovakia

*E-mail of corresponding author: filip.pastorek@rc.uniza.sk

ISSN $1335-4205$ (Print), ISSN 2585-7878 (Online) / @ 2020 UNIVERSITY OF ZILINA 
Table 1 Chemical composition of the Domex 700 steel (wt. \%)

\begin{tabular}{ccccccccccc}
\hline $\mathrm{C}$ & $\mathrm{Si}$ & $\mathrm{Mn}$ & $\mathrm{S}$ & $\mathrm{P}$ & $\mathrm{Al}$ & $\mathrm{Nb}$ & $\mathrm{V}$ & $\mathrm{Ti}$ & $\mathrm{Fe}$ \\
\hline 0.110 & 0.090 & 0.720 & 0.009 & 0.007 & 0.015 & 0.094 & 0.210 & 0.130 & balance \\
\hline
\end{tabular}

Table 2 Parameters of the phosphating process

\begin{tabular}{ccccc}
\hline Demi. $\mathrm{H}_{2} \mathrm{O}$ & $\begin{array}{c}\mathrm{H}_{3} \mathrm{PO}_{4} \\
(85.8 \mathrm{wt} . \%)\end{array}$ & $\begin{array}{c}\mathrm{MnO}_{2} \\
(99.9 \mathrm{wt} \%)\end{array}$ & $\begin{array}{c}\text { Ultrafine steel wool } \\
\text { (grade 0000) }\end{array}$ & Temperature range \\
\hline $500 \mathrm{ml}$ & $7.5 \mathrm{~g} / 1 \mathrm{l}$ & $7.5 \mathrm{~g} / 1 \mathrm{l}$ & $2.5 \mathrm{~g} / 1 \mathrm{l}$ & $50-90^{\circ} \mathrm{C}$ \\
\hline
\end{tabular}

Table 3 Chemical composition of the MnP layers formed on a ground surface of the Domex 700 steel at various phosphating temperatures (wt. \%)

\begin{tabular}{|c|c|c|c|c|}
\hline Phosp. temperature & $\mathrm{O}$ & $\mathrm{Mn}$ & $\mathrm{P}$ & $\mathrm{Fe}$ \\
\hline $50{ }^{\circ} \mathrm{C}$ & 5.3 & 2.9 & 0.9 & 91.0 \\
\hline $60{ }^{\circ} \mathrm{C}$ & 23.2 & 10.5 & 7.9 & 57.2 \\
\hline $70^{\circ} \mathrm{C}$ & 28.9 & 12.7 & 10.7 & 47.7 \\
\hline $80^{\circ} \mathrm{C}$ & 35.0 & 15.8 & 13.4 & 35.8 \\
\hline $90^{\circ} \mathrm{C}$ & 45.6 & 33.6 & 16.1 & 5.0 \\
\hline
\end{tabular}

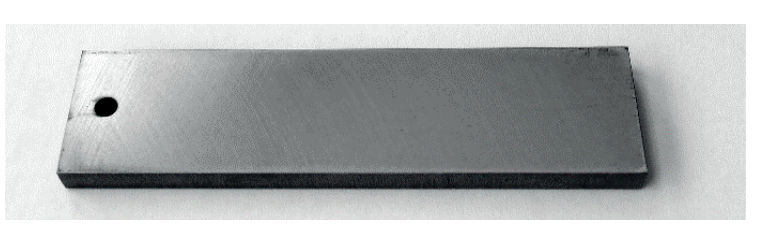

Figure 1 Sample of Domex 700 steel designed both for phosphating and electrochemical tests

as the test medium for all the electrochemical tests. All the electrochemical measurements were performed at $22 \pm 2^{\circ} \mathrm{C}$.

A technique with a constant potential change per time unit was used for the PD measurements. The PD tests were performed over the potential range from $-250 \mathrm{mV}$ to $+300 \mathrm{mV}$ vs. an open circuit potential $\left(E_{O C}\right)$ value, after 5 minutes of stabilization in the $0.1 \mathrm{M} \mathrm{NaCl}$ test environment. The constant change of applied potential during the measurements was 1 $\mathrm{mV} \cdot \mathrm{s}^{-1}$. The measured area of the samples was $1 \mathrm{~cm}^{2}$. The Tafel analysis of the measured curves was performed using the EC-Lab V11.10 software.

The EIS measurements were realized after 5 minutes of stabilization, too. The measurements were performed in the frequency range from $100 \mathrm{kHz}$ to $10 \mathrm{mHz}$ with the frequency 10 times per decade. The amplitude of the applied AC voltage was $10 \mathrm{mV}$ around the open circuit potential value $\left(E_{O C}\right)$. The output of the EIS measurements were represented by the Nyquist diagrams, which were analysed by the equivalent circuits with the EC-Lab V11.10 software.

The samples were pre-treated by grinding with a p500 grit $\mathrm{SiC}$ paper to provide a uniform and homogeneous substrate prior to MnP phosphating. The grain size of the abrasive paper used was chosen based on the previous experimental works and the experience of the authors with the manganese phosphating process $[7,12]$. Prior to the phosphating process, the samples were thoroughly degreased and cleaned in an ultrasonic cleaner for 15 minutes before being dried with a stream of air. The phosphating process was performed by immersing the samples in the phosphating bath. The samples were placed vertically. After the phosphating process, the samples were washed with demineralised water and dried with a stream of air. The individual parameters of the phosphating process are shown in Table 2.

\section{Results and discussion}

Created $\mathrm{MnP}$ layer is composed of $\mathrm{Mn}$ from the solution and $\mathrm{Fe}$ from the steel wool/matrix. Depending on the $\mathrm{Mn} /$ $\mathrm{Fe}$ ratio the chemical composition of the layer is (Mn, $\mathrm{Fe})_{3}\left(\mathrm{PO}_{4}\right)_{2}-2(\mathrm{Mn}, \mathrm{Fe}) \mathrm{HPO}_{4}-4 \mathrm{H} 2 \mathrm{O}$, where $\mathrm{Fe}$ and $\mathrm{Mn}$ are interchangeable. The total $\mathrm{Mn}$ and $\mathrm{Fe}$ content in the well prepared $\mathrm{MnP}$ structure is $39-40 \mathrm{wt} \%$ [7, 13-14]. However, as proved in our previous study, higher Mn content helps to reach better corrosion properties of the layer [15]. Therefore, it is important to know the chemical composition of the MnP layers for the deeper evaluation of the surface properties. The morphology and chemical composition of the $\mathrm{MnP}$ layers formed at the different temperatures are documented in Figure 2 and in Table 3. As can be seen, the change in the phosphating temperature significantly affects the formation of the MnP layer. As the temperature increase, a more compact and homogeneous MnP layer is formed, a direct effect of which on the surface layer composition was as detected by the EDX analysis. Figure 2a reveals that MnP phosphating of the tested HSLA steel in the chosen phosphating solution 


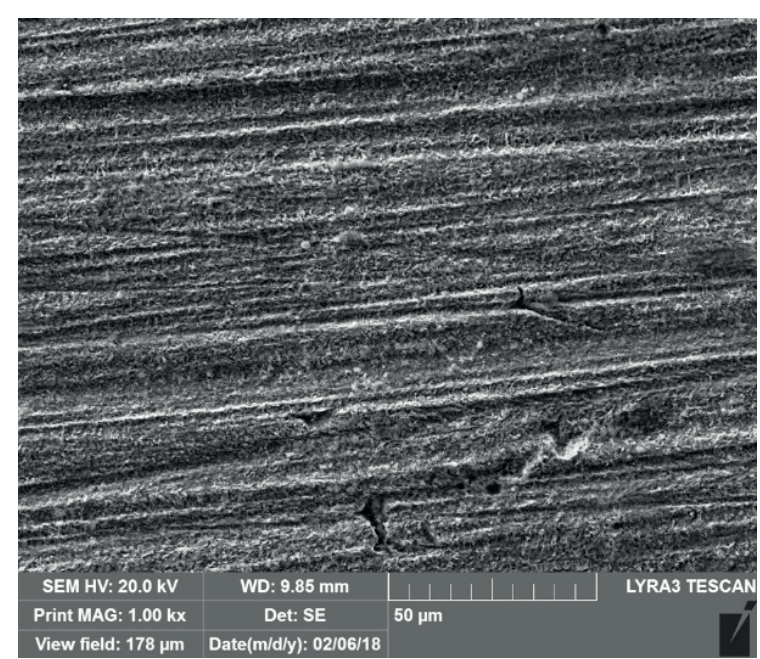

$50{ }^{\circ} \mathrm{C}$

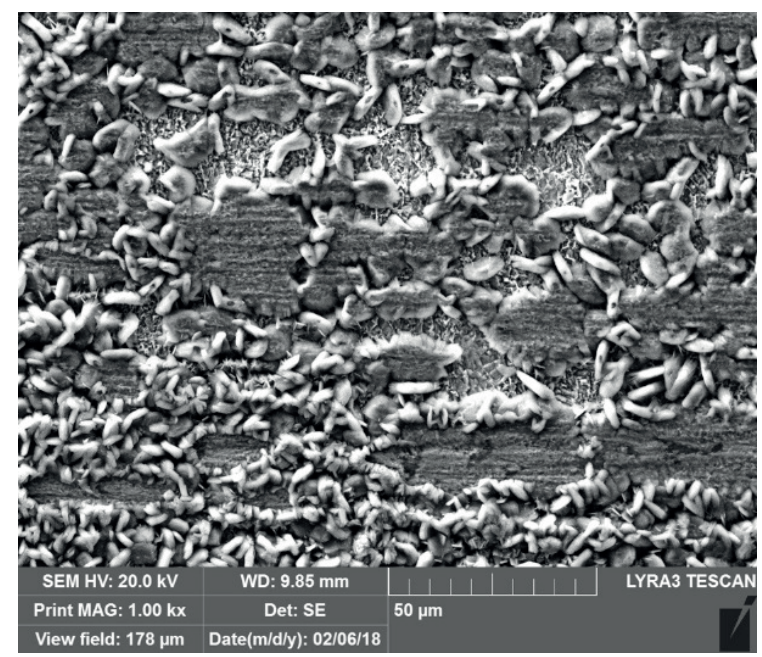

$70^{\circ} \mathrm{C}$

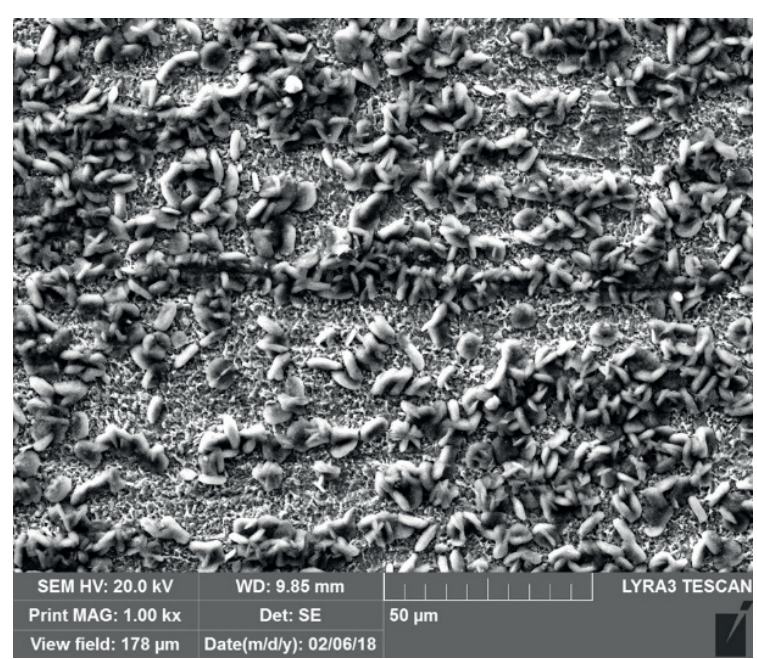

$60^{\circ} \mathrm{C}$

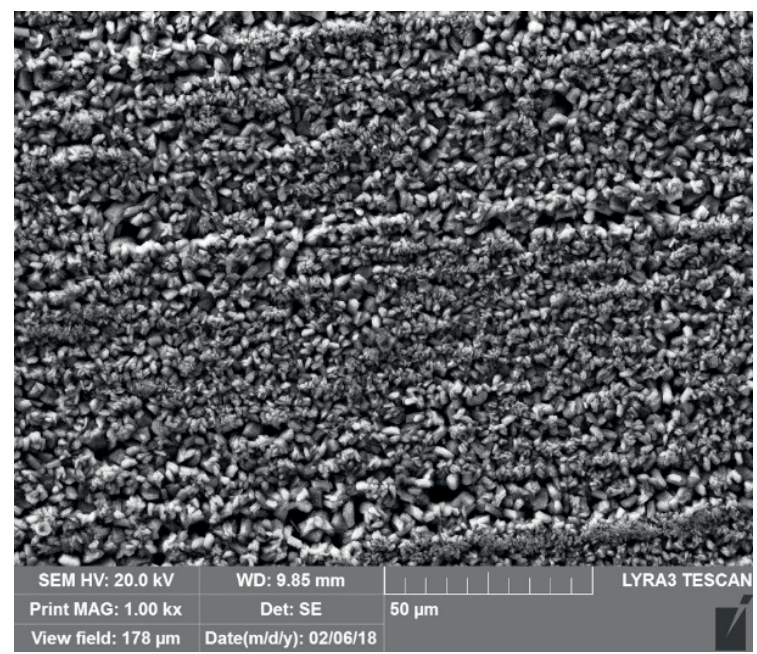

$80^{\circ} \mathrm{C}$

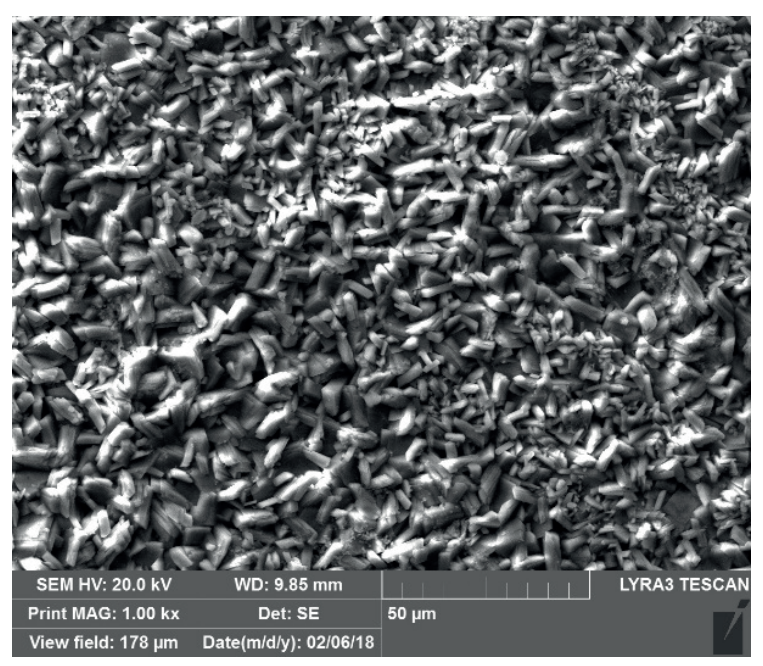

$90{ }^{\circ} \mathrm{C}$

Figure 2 Morphology of the MnP layers formed on a ground surface of the Domex 700 steel at various phosphating temperatures

is very unsatisfactory at temperatures up to $60{ }^{\circ} \mathrm{C}$ as almost no MnP layer is visually detectable on the steel surface. Even the surface morphology after the final grinding operation is still clearly visible on the phosphate surface. The formation of just a fine MnP film is proved by the small percentage of $\mathrm{Mn}$ and $\mathrm{P}$ in the surface layer (Table 3). The $91 \% \mathrm{Fe}$ content in the surface layer demonstrates that the performed EDX analysis detected the matrix. Thus, there is no thermodynamic 


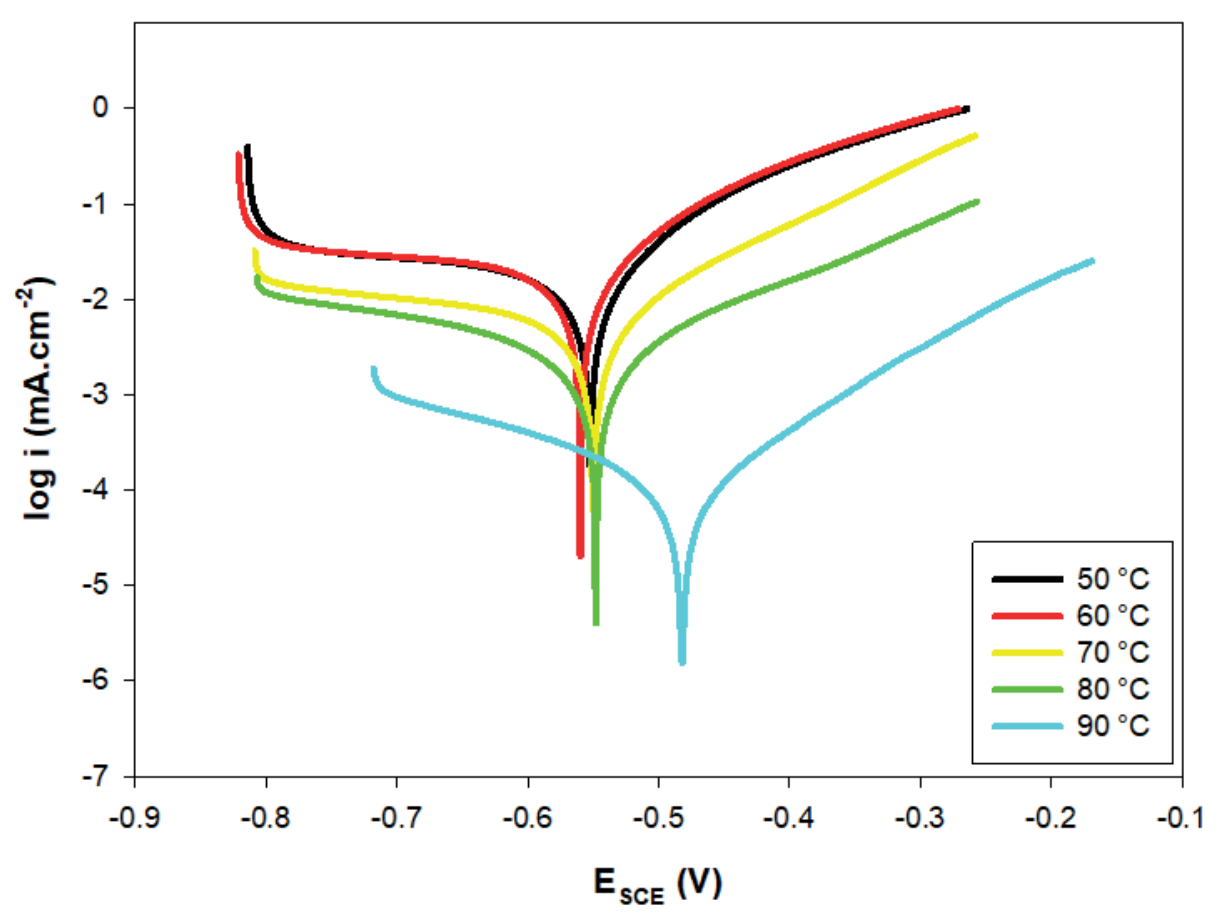

Figure 3 PD curves of the MnP layers formed on a ground surface of the Domex 700 steel at various phosphating temperatures

assumption for a serious nucleation of the $\mathrm{MnP}$ layer crystals at the low temperatures (below $50{ }^{\circ} \mathrm{C}$ ). At $60{ }^{\circ} \mathrm{C}$, the conditions for the $\mathrm{MnP}$ layer formation are slightly better, as demonstrated by the nucleation and distinct local formation of the MnP facets. Although the layer is non-compact, the significant increase in $\mathrm{Mn}$ and $\mathrm{P}$ content measured by the EDX analysis presents superior thermodynamic conditions for the $\mathrm{MnP}$ layer formation to the phosphating at $50{ }^{\circ} \mathrm{C}$. The trend of the $\mathrm{MnP}$ growth at $70{ }^{\circ} \mathrm{C}$ is very similar to the one at $60{ }^{\circ} \mathrm{C}$ apart from the slight increase in $\mathrm{Mn}$ and $\mathrm{P}$ content. The morphological change is negligible. Similar results with the local smooth facets formation at $70{ }^{\circ} \mathrm{C}$ were also obtained by Wang et al. [10]. However, the very high Fe content in the surface layer still confirms the fact that a significant part of the surface is still not covered by the $\mathrm{MnP}$ layer. When the phosphating temperature reaches 80 ${ }^{\circ} \mathrm{C}$ the relatively homogeneous layer of the fine MnP crystals is formed that copies the surface morphology after grinding. Thus, the temperature of $80{ }^{\circ} \mathrm{C}$ is the limit for reaching the thermodynamic conditions allowing a visually continuous $\mathrm{MnP}$ layer formation after 75 minutes of phosphating. However, the Fe content is still very significant meaning that the layer is very thin and porous allowing the EDX to detect the matrix. Only phosphating at the temperature close to the boiling point $\left(90^{\circ} \mathrm{C}\right)$ allowed the increase of the diffusion kinetics of the nucleation process and the growth of the MnP crystals to such an extent that the formation of a thick and homogenous $\mathrm{MnP}$ layer was possible. Although there is only a $10{ }^{\circ} \mathrm{C}$ difference to the previous phosphating temperature $\left(80^{\circ} \mathrm{C}\right)$, this temperature change has a critical effect on the phosphating process efficiency. The $\mathrm{MnP}$ crystals formed at $90{ }^{\circ} \mathrm{C}$ were considerably thicker and the layer was more compact, as proven also by results of EDX analysis, where a significant decrease in the Fe content and an increase in the $\mathrm{Mn}$ content were detected. In addition, the Mn content (33.6 wt.\%) markedly exceeded the recorded Fe content (5.0 wt.\%). This fact does not only indicate the reduction of pores and layer defects, but also the thermodynamic state of the phosphating system where the phosphate $\mathrm{Mn}_{3}\left(\mathrm{PO}_{4}\right)_{2}$ $2 \mathrm{MnHPO}_{4}-4 \mathrm{H}_{2} \mathrm{O}$ is preferably formed in the $\mathrm{MnP}$ structure.

The results from the morphological and chemical analysis of the tested layers were also supported by the electrochemical tests to provide a more comprehensive assessment of the quality of the formed layers. The measured PD curves and EIS curves of the created MnP layers at different phosphating temperatures are shown in Figures 3 and 4. The individual electrochemical characteristics obtained by the analysis of these curves are shown in Table 4. It was proven, that the higher temperatures of phosphating lead to lower values of the corrosion current density $i_{\text {Corr }}$ and the corrosion rate $v_{\text {Corr }}$. This confirms the formation of a protective layer on the surface of the base material and a gradual increase in the corrosion resistance in the aggressive chloride-containing solution. The decrease of the $i_{\text {Corr }}$ values is gradual and fluent up to $80{ }^{\circ} \mathrm{C}$. However, the layer formed at $90{ }^{\circ} \mathrm{C}$ reached the $i_{\text {Corr }}$ value of 2 orders of magnitude lower compared to one formed at $80{ }^{\circ} \mathrm{C}$. This radical difference between two phosphating temperatures supports the similar differences reached by the EDX and morphology observations. The corrosion potential values did not show significant change in either direction in the range of phosphating temperatures from $50{ }^{\circ} \mathrm{C}$ to $80{ }^{\circ} \mathrm{C}$. Hence, it can be stated that from the thermodynamic point of view neither the character of the formed layer nor the thermodynamic stability of the 


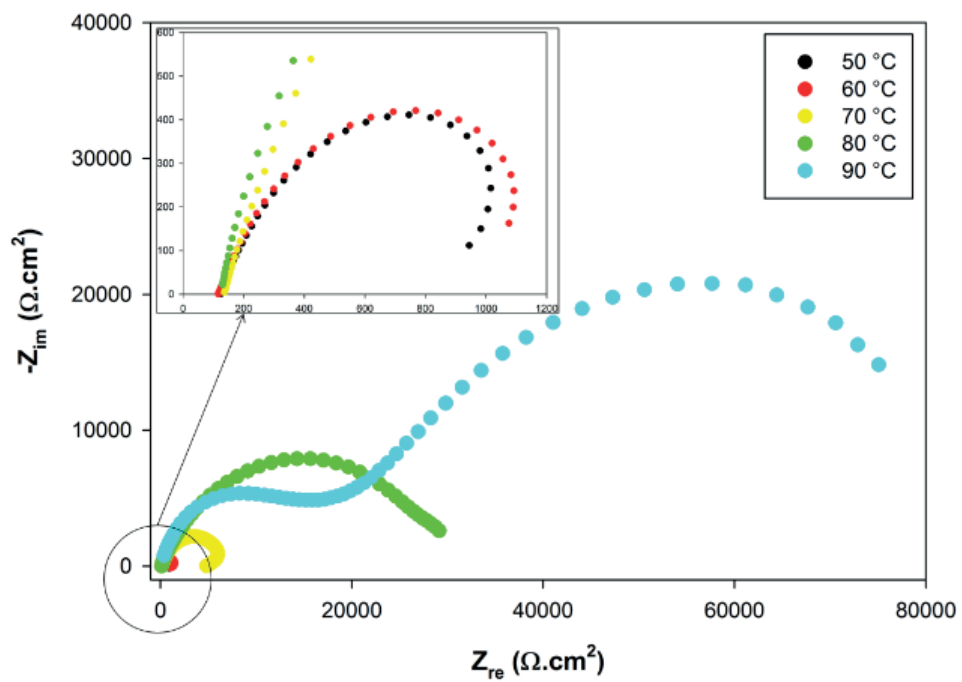

Figure 4 Nyquist diagrams of the MnP layers formed on a ground surface of Domex 700 steel at various phosphating temperatures

Table 4 Electrochemical corrosion characteristics of the MnP layers formed on a ground surface of the Domex 700 steel at various phosphating temperatures

\begin{tabular}{|c|c|c|c|c|c|c|c|c|}
\hline $\begin{array}{l}\text { Phosp. } \\
\text { temp. }\end{array}$ & $\begin{array}{l}\mathrm{E}_{\text {Corr }} \\
(\mathrm{mV})\end{array}$ & $\begin{array}{c}\mathrm{i}_{\text {Corr }} \\
\left(\mu \mathrm{A} \cdot \mathrm{cm}^{-2}\right)\end{array}$ & $\mathrm{v}_{\text {Corr }}\left(\mu \mathrm{m}\right.$. year $\left.^{1}\right)$ & $\begin{array}{c}\mathrm{R}_{\mathrm{P1}} \\
\left(\Omega . \mathrm{cm}^{2}\right)\end{array}$ & $\begin{array}{c}\mathrm{R}_{\mathrm{P} 2} \\
\left(\Omega . \mathrm{cm}^{2}\right)\end{array}$ & $\begin{array}{c}\mathrm{R}_{\mathrm{P}} \\
\left(\Omega . \mathrm{cm}^{2}\right)\end{array}$ & $\begin{array}{c}\mathrm{CPE}_{1} \\
\left(10^{-6} \cdot \mathrm{F} \cdot \mathrm{s}^{\mathrm{n}-1}\right)\end{array}$ & $\begin{array}{c}\mathrm{CPE}_{2} \\
\left(10^{-6} \cdot \mathrm{F} \cdot \mathrm{s}^{\mathrm{n}-1}\right)\end{array}$ \\
\hline \multirow{2}{*}{$50{ }^{\circ} \mathrm{C}$} & -552 & 11.78 & 273 & 1250 & \multirow{2}{*}{ - } & 1250 & 477 & \multirow{2}{*}{ - } \\
\hline & \pm 9 & \pm 1.13 & \pm 21 & \pm 51 & & \pm 51 & \pm 21 & \\
\hline \multirow{2}{*}{$60{ }^{\circ} \mathrm{C}$} & -561 & 10.97 & 255 & 1295 & \multirow{2}{*}{ - } & 1295 & 457 & \multirow{2}{*}{ - } \\
\hline & \pm 11 & \pm 1.21 & \pm 18 & \pm 61 & & \pm 61 & \pm 23 & \\
\hline \multirow{2}{*}{$70{ }^{\circ} \mathrm{C}$} & -551 & 4.57 & 106 & 5972 & \multirow{2}{*}{ - } & 5972 & 23 & \multirow{2}{*}{ - } \\
\hline & \pm 8 & \pm 0.87 & \pm 9 & \pm 195 & & \pm 195 & \pm 5 & \\
\hline \multirow{2}{*}{$80^{\circ} \mathrm{C}$} & -548 & 2.31 & 54 & 27788 & & 27788 & 3.3 & \\
\hline & \pm 13 & \pm 0.51 & \pm 4 & \pm 347 & & \pm 347 & \pm 0.6 & \\
\hline \multirow{2}{*}{$90{ }^{\circ} \mathrm{C}$} & -482 & 0.07 & 1.7 & 66140 & 16214 & 82354 & 0.06 & 7.4 \\
\hline & \pm 7 & \pm 0.01 & \pm 0.2 & \pm 1234 & \pm 201 & \pm 1435 & \pm 0.01 & \pm 0.5 \\
\hline
\end{tabular}

whole system changes markedly. However, by increasing the phosphating temperature up to $90^{\circ} \mathrm{C}$, a step change $(66 \mathrm{mV})$ is achieved, similarly to the case of the current density. In this case, a significant decrease in the Fe content of the surface layer and an increase in the Mn content are responsible for the potential shift to more positive values. This results in the better thermodynamic stability of the surface layer in the corrosion test medium.

The EIS measurements and Nyquist diagram analysis provide a comprehensive view of the corrosion resistance of the formed MnP coating on the tested HSLA steel. The most relevant electrochemical parameter in this area is the polarization resistance $R_{p}$, which expresses the resistance of the surface layer to the corrosion process [16-17]. In a more complex systems, this polarization resistance is given by the sum of the partial resistances $R_{p 1}$ and $R_{p 2}$. This situation appears when the measured Nyquist diagram is composed of two capacitive loops. Only one capacitive loop was recorded in the Nyquist diagrams measured up to $80{ }^{\circ} \mathrm{C}$ on the samples. This fact expresses a situation where the formed layer does not reach the level of compactness necessary to form its own impedance loop. However, the gradual increasing of the MnP layer quality, reached by increasing the phosphating temperature, caused the reduction in charge transfer between the corrosive medium and the base material, which is documented by the gradual increase of the $R_{p}$ values (Table 4 ). The considerably higher $R_{p}$ value of the MnP layer reached after phosphating at 90 ${ }^{\circ} \mathrm{C}$ compared to $80{ }^{\circ} \mathrm{C}$, is caused due to both a significant reduction in the charge transfer through the base material / environment interface and an additive effect of the $\mathrm{MnP}$ layer resistance itself. The layer formed at this temperature reveals a high level of compactness that allows formation of the second capacitive loop in the Nyquist diagram. The decreasing values of the constant phase element $C P E_{1}$ also documents e reduction of the active surface area of the base material and the increasing thickness of the formed layer. The quality of the $\mathrm{MnP}$ layer, formed at $90{ }^{\circ} \mathrm{C}$, is evident very well from this parameter as it reached the $C P E_{1}$ value of 4 orders of magnitude lower compared to those prepared at 50 or $60{ }^{\circ} \mathrm{C}$. As the only one MnP layer (formed at $90{ }^{\circ} \mathrm{C}$ ) revealed 2 capacitive loops, the value of the constant phase element $C P E_{2}$, related to the electrolyte penetration ability of the formed layer, could not be 
compared to the other ones. The phosphating temperature of $90{ }^{\circ} \mathrm{C}$ was also found to be optimal by Wang et al. [10], who observed the effect of higher temperatures (70 - 90 ${ }^{\circ} \mathrm{C}$ ) of phosphating on morphology and electrochemical characteristics of a different steel type. Thus, it can be concluded that despite the certain specifics and differences in the phosphating process, it is necessary to maintain the phosphating bath temperature of at least $90{ }^{\circ} \mathrm{C}$ throughout the phosphating, regardless of the fact that the phosphated material is a standard or HSLA steel.

\section{Conclusions}

Based on the measured data and analyses the following was concluded:

A. There are several step changes during the manganese phosphating of the Domex 700 HSLA steel depending on the process temperature resulting in the quality and surface properties differences of the formed $\mathrm{MnP}$ layers.
B. The threshold for forming a visually compact $\mathrm{MnP}$ layer is to maintain the phosphating temperature of at least $80^{\circ} \mathrm{C}$.

C. The chemical composition of the MnP layer with the higher Mn content than Fe is ensured by phosphating at the temperature of $90{ }^{\circ} \mathrm{C}$

D. The most compact $\mathrm{MnP}$ layer with the highest corrosion resistance and electrochemical stability in the aqueous medium containing chloride ions is achieved at the highest tested phosphating temperature $\left(90^{\circ} \mathrm{C}\right)$.

\section{Acknowledgements}

Authors are grateful for the support in experimental works to Slovak Research and Development Agency by the projects No. APVV-15-0120, APVV-16-0300, APVV-16-0276 and APVV-14-0772.

\section{References}

[1] GARCIA, C. I. Chapter 6 - High strength low alloyed (HSLA) steels. In: Automotive steels. Design, metallurgy, processing and applications. University of Pittsburgh:Woodhead Publishing, 2016, p. 145-167. ISBN 0081006535

[2] LI, J., WU, J., WANG, Z., ZHANG, S., WU, X., HUANG, Y., LI, X. The effect of nanosized NbC precipitates on electrochemical corrosion behavior of high-strength low-alloy steel in 3.5\% NaCl solution. International Journal of Hydrogen Energy [online]. 2017, 42(34), p. 22175-22184 [accessed 2019-10-09]. ISSN 0360-3199. Available from: https://doi.org/10.1016/j.ijhydene.2017.03.087

[3] KIM, W.K., KOH,S.U., YANG, B. Y., KIM, K.Y.Effectof environmentalandmetallurgicalfactors onhydrogeninduced cracking of HSLA steels. Corrosion Science [online]. 2008, 50, p. 3336-3342 [accessed 2019-10-09]. ISSN 0010-938X. Available from: https://doi.org/10.1016/j.corsci.2008.09.030

[4] PASTOREK, F., BORKO, K., DUNDEKOVA, S., FINTOVA, S., HADZIMA, B. Elektrochemicke korozne charakteristiky fosfatovanej ocele S355J2 v prostredi siranov / Electrochemical corrosion characteristics of phosphated S355J2 steel in sulfate environment (in Slovak). Koroze a ochrana materialu[online]. 2016, 60(4), p. 107-113. [accessed 2019-10-09]. ISSN 1804-1213. Available from: https://www.degruyter.com/downloadpdf/j/kom.2016.60.issue-4/kom-2016-0017/ kom-2016-0017.pdf

[5] PASTOREK, F., BORKO, K., FINTOVA, S., KAJANEK, D., HADZIMA, B. Effect of surface pre-treatment on quality and electrochemical corrosion properties of manganese phosphate on S355J2 HSLA steel. Coatings [online]. 2016, 6(4), p. 46. [accessed 2019-10-09]. ISSN 2079-6412. Available from: https://doi.org/10.3390/coatings6040046

[6] OLSOVSKY, M. Zaklady povrchovej upravy kovov / Basics of surface treatment of metals (in Slovak). Novaky: MSM Martin, 2015. ISBN 978-80-971929-9-0.

[7] GALVAN-REYES, C. SALINAS-RODRIGUEZ, A. FUENTES-ACEITUNO, J. C. Degradation and crystalline reorganization of hureaulite crystals during the manganese phosphating of a high strength steel. Surface and Coatings Technology [online]. 2015, 275, p. 10-20. [accessed 2019-10-09]. ISSN 0257-8972. Available from: https://doi.org/10.1016/j.surfcoat.2015.05.030

[8] KELLY, R. G., SCULLY, J. R., SHOESMITH, D., BUCHHEIT, R. G. Electrochemical techniques in corrosion science and engineering. Boca Raton, USA: CRC Press, 2003. ISBN 978-0-8247-9917-5.

[9] NARAYANAN, T. S. N. Surface pretreatment by phosphate conversion coatings - a review. Reviews on Advanced Materials Science [online]. 2005, 9(2), p. 130-177. [accessed 2019-10-09]. ISSN 1605-8127. Available from: http://www.ipme.ru/e-journals/RAMS/no_2905/narayanan.pdf

[10] WANG, C. M., LIAU, H. C., TSAI, W. T. Effects of temperature and applied potential on the microstructure and electrochemical behavior of manganese phosphate coating. Surface and coatings Technology [online]. 2006, 201(6), p. 2994-3001. [accessed 2019-10-09]. ISSN 0257-8972. Available from: https://doi.org/10.1016/j.surfcoat.2006.06.010 
[11] HIVART, P., HAUW, B., BRICOUT, J. P., OUDIN, J. Seizure behaviour of manganese phosphate coatings according to the process conditions. Tribology International [online]. 1997, 30(8), p. 561-570. [accessed 2019-10-09]. ISSN 0301-679X. Available from: https://doi.org/10.1016/S0301-679X(97)00019-4

[12] GALVAN-REYES, C. FUENTES-ACEITUNO, J. C. SALINAS-RODRIGUEZ, A. The role of alkalizing agent on the manganese phosphating of a high strength steel part 2: The combined effect of $\mathrm{NaOH}$ and the amino group $\left(\mathrm{NH}_{4} \mathrm{OH}\right.$, mono-ethanolamine and NH4NO3) on the degradation stage of the phosphating mechanism. Surface and Coatings Technology [online]. 2016, 299, p. 113-122. [accessed 2019-10-09]. ISSN 0257-8972. Available from: https://doi.org/10.1016/j.surfcoat.2016.04.059

[13] BOGI, J., MACMILlAN, R. Phosphate conversion coatings on steel. Journal of Materials Science [online]. 1997, 12(11), p. 2235-2240. [accessed 2019-10-09]. ISSN 1573-4803. Available from: https://link.springer.com/article/10.1007/BF00552245

[14] KOZLOWSKI, A. Dry friction of manganese phosphate coatings on steel and cast iron. Electrodeposition and Surface Treatment [online]. 1974, 2(2), p. 109-122. [accessed 2019-10-09]. ISSN 0300-9416. Available from: https://doi.org/10.1016/0300-9416(74)90009-1

[15] HADZIMA, B., PASTOREK, F., BORKO, K., FINTOVA, S., KAJANEK, D., BAGHERIFARD, S., GHOLAMI-KERMANSHAHI, M., TRSKO, L., PASTORKOVA, J., BREZINA, J. Effect of phosphating time on protection properties of hurealite coating: differences between ground and shot peened HSLA steel surface. Surface and Coatings Technology [online]. 2019, 375, p. 608-620. [accessed 2019-10-09]. ISSN 0257-8972. Available from: https://doi.org/10.1016/j.surfcoat.2019.07.056

[16] MINARIK, P., KRAL, R., HADZIMA, B. Substantially higher corrosion resistance in AE42 magnesium alloy through corrosion layer stabilization by ECAP treatment. Acta Physica Polonica-Series A General Physics [online]. 2012, 122(3), p. 614. [accessed 2019-10-09]. ISSN 1898-794X. Available from: http://psjd.icm.edu.pl/psjd/element/bwmeta1. element.bwnjournal-article-appv122z3p46kz

[17] BUKOVINOVA, L., HADZIMA, B. Electrochemical characteristics of magnesium alloy AZ31 in Hank's solution. Corrosion Engineering, Science and Technology [online]. 2012, 47(5), p. 352-357. [accessed 2019-10-09]. ISSN 1478-422X. Available from: https://doi.org/10.1179/1743278212Y.0000000033 